\title{
Electric Field-Assisted Delivery of Photofrin to Human Breast Carcinoma Cells
}

\author{
Joanna Wezgowiec $\cdot$ Maria B. Derylo $\cdot$ Justin Teissie $\cdot$ \\ Julie Orio $\cdot$ Marie-Pierre Rols · Julita Kulbacka • \\ Jolanta Saczko $\cdot$ Malgorzata Kotulska
}

Received: 19 December 2012/ Accepted: 8 March 2013/Published online: 2 April 2013

(C) The Author(s) 2013. This article is published with open access at Springerlink.com

\begin{abstract}
The influence of electroporation on the Photofrin uptake and distribution was evaluated in the breast adenocarcinoma cells (MCF-7) and normal Chinese hamster ovary cells (CHO) lacking voltage-dependent channels in vitro. Photofrin was used at a concentration of 5 and $25 \mu \mathrm{M}$. The uptake of Photofrin was assessed using flow cytometry and fluorescence microscopy methods. Cells viability was evaluated with crystal violet assay. Our results indicated that electropermeabilization of cells, in the presence of Photofrin, increased the uptake of the photosensitizer. Even at the lowest electric field intensity $(700 \mathrm{~V} / \mathrm{cm})$ Photofrin transport was enhanced. Flow cytometry results for MCF-7 cells revealed $\sim 1.7$ times stronger fluorescence emission intensity for cells exposed to Photofrin and electric field of $700 \mathrm{~V} / \mathrm{cm}$ than cells treated with Photofrin alone. Photofrin was effective only when irradiated with blue light. Our studies on combination of photodynamic reaction with electroporation suggested improved effectiveness of the treatment and showed intracellular distribution of Photofrin. This approach may
\end{abstract}

J. Wezgowiec $\cdot$ M. B. Derylo $\cdot$ M. Kotulska $(\bowtie)$

Institute of Biomedical Engineering and Instrumentation,

Wrocław University of Technology, Wybrzeze Wyspianskiego

27, 50-370 Wrocław, Poland

e-mail: malgorzata.kotulska@pwr.wroc.pl

J. Teissie $\cdot$ J. Orio $\cdot$ M.-P. Rols

CNRS, Institut de Pharmacologie et de Biologie Structurale

(IPBS), 205 route de Narbonne, 31077 Toulouse, France

J. Teissie $\cdot$ J. Orio $\cdot$ M.-P. Rols

Université de Toulouse, UPS, IPBS, 31077 Toulouse, France

J. Kulbacka · J. Saczko

Department of Medical Biochemistry, Wrocław Medical

University, Chalubinskiego 10, 50-368 Wrocław, Poland be attractive for cancer treatment as enhanced cellular uptake of Photofrin in MCF-7 cells can help to reduce effective dose of the photosensitizer and exposure time in this type of cancer, diminishing side effects of the therapy.

Keywords Breast cancer cells · Electropermeabilization · Electroporation · Photodynamic reaction · Photofrin

\section{Introduction}

Photodynamic therapy (PDT) is a treatment modality applied in a number of cancer and noncancer diseases. It involves administration of a photosensitive agent (called photosensitizer), which is activated with a light of a specific wavelength. Reactive oxygen species (ROS) are generated and interact with cellular components, leading to oxidative stress and cell death. Therapeutic effect of PDT results from direct cytotoxicity, vascular damage and immunological response. The mode of cell death depends on several factors, such as properties of a photosensitizer, cell type, drug and light dose. Selectivity of PDT is achieved by the localized delivery of light and localized accumulation of a photosensitizer (Agostinis et al. 2011; Choudhary et al. 2009; Stamati et al. 2010; Robertson et al. 2009).

The ideal photosensitizer accumulates selectively in a tumor tissue, and has a high photocytotoxicity but minimal dark toxicity. It should also be efficiently removed from the body. Photosensitizer uptake and localization is particularly important for the resulting photodamage, due to short migration distance of singlet oxygen. To improve transport of the photosensitizer, several systems have been proposed: quantum dots (Samia et al. 2006), emulsions (Marchal et al. 2007), liposomes, nanoparticles (Josefsen and Boyle 
2008) and methods such as ultrasounds, iontophoresis, electrophoresis and electroporation (for a review, see Donnelly et al. 2009; Juzeniene et al. 2007; Kotulska et al. 2013).

Electroporation (EP, electropermeabilization) is a reversible process of transient increase of the cell membrane permeability, due to exposure to external electric field pulses of high intensity. This technique, depending on the applied pulses parameters, may be used in many different disciplines. The most-developed area of its applications is medicine. Reversible EP can be used for enhancement of anticancer therapies. A combination of EP with chemotherapy is called electrochemotherapy (ECT) and it is already successfully used in clinical practice to overcome the problem with drug delivery. Two chemotherapeutic drugs are the best candidates for ECT: bleomycin and cisplatin (Gehl 2003; Kotulska 2007; Miklavcic et al. 2012; Mir 2006; Rols 2006; Serša et al. 2008). Another method, electrogene therapy, is currently under preclinical trials. It is an electrically assisted nonviral method of nucleic acid delivery (Chabot et al. 2013; Rols 2010; Sukharev et al. 1992). Irreversible EP has been proposed as a method of nonthermal, minimally invasive ablation (Davalos et al. 2005). In addition to numerous medical applications, EP is a very useful technique for biology, biotechnology and food industry (Kanduser and Miklavcic 2008).

In the area of PDT the vast majority of research studies new photosensitizers, and very few are focused on innovative systems for photosensitizers delivery. Several studies considered combination of EP with PDT for enhancement of the photosensitizers transport. Labanauskiene et al. (2009) demonstrated that EP improved an access of two photosensitizers: chlorine e6 (C e6) and aluminium phthalocyanine tetrasulfonate (AlPcS4) to murine hepatoma MH22A cells. EP-enhanced cellular uptake of photosensitizers has a significant impact on the viability of cells. Ward et al. (1997) described the effects of electric-field enhanced activation of hematoporphyrin derivate $(\mathrm{HpD})$ on HeLa cells. The results demonstrated an increased degree of cell lysis, even in nonirradiated cells. The authors suggest that some form of $\mathrm{HpD}$ activation event was occurring during the application of the electric pulses. Lambreva et al. (2004) demonstrated that EP of cell membrane supported penetration of macromolecular chromophore dextrans acting as photosensitizers. The human histolytic lymphoma U-935 cells and the human chronic myeloid, leukemia K-562 cells reach high ratios of necrotic cells. To overcome one of the major drawbacks of systemic administration and to reduce drug dose, Johnson et al. studied potential improvement of local delivery of photosensitizers. As a result, with pulsed electric field delivery, almost all amount of the drug was delivered to the target region, reducing the systemic toxicity and time of incubation. The authors believe that enhanced cutaneous delivery of methylene blue and ALA was due to the combination of de novo permeabilization of the stratum corneum, passive diffusion through the permeabilization sites, and electrophoretic and electro-osmotic transport (Johnson et al. 1998, 2002). In our previous studies, we assessed the influence of EP on PDT with $\mathrm{HpD}$, which is a less purified product than Photofrin (Kulbacka et al. 2011).

Photofrin (porfimer sodium) is a commercial, purified hematoporphyrin derivative. This is a mixture of compounds including hematoporphyrin monomers, dimmers and oligomers and it has not been fully characterized. Photofrin is a first generation photosensitizer approved for clinical applications and used to treat a variety of tumors, with successful therapeutic results. However, the main disadvantage associated with Photofrin is prolonged skin photosensitivity and relatively low specificity for tumor tissue (Choudhary et al. 2009; Samia et al. 2006; Berg et al. 2011; Ferreira et al. 2009).

The concept of Photofrin-mediated PDT enhanced with EP has not been studied yet; however, there are many studies on Photofrin-mediated PDT (Hajri et al. 2002; Luo et al. 2010; Tong et al. 2000; Chang et al. 2008; Korbelik and Krosl 1996; Henderson et al. 2000; Schweitzer 2001; Jiang et al. 1998; Kulbacka et al. 2010). Several studies on Photofrin transport and accumulation mechanism were also conducted. Due to its hydrophobicity, Photofrin concentrates in the mitochondria, endoplasmic reticulum, cytoplasmic and nuclear membrane and perinuclear region of the cytoplasm of cells in vitro. A potentially important target for PDT is cardiolipin-a phospholipid found in the inner membrane of mitochondria and at the contact sites between the inner and outer membranes. It was demonstrated that lipophilic sensitizers are taken up by cells following an LDL receptor-mediated endocytosis (Teiten et al. 2001; Peng et al. 1996; Rodriguez et al. 2008; Morgan and Oseroff 2001; Chwilkowska et al. 2003; Wilson et al. 1997). After a brief incubation $(3 \mathrm{~h})$, the main target site of Photofrin is plasma membrane. After a prolonged incubation $(24 \mathrm{~h})$, it moves to intracellular compartments: the Golgi complex, mitochondria, lysosomes-the specific pattern of localization depends on the cell type (Chang et al. 2008; Wilson et al. 1997; Hsieh et al. 2003).

Enhancement of Photofrin delivery by EP may not only change the amount of incorporated photosensitizer, but also the time and the site of its accumulation. It is particularly significant as the type of cell death depends on the localization of a photosensitizer in cells. When plasma membrane is the main target, upon irradiation the cell death phenotype is necrosis like (Chang et al. 2008; Hsieh et al. 2003). Dellinger showed that short-time incubation of cells 
with high concentrations of Photofrin results in a leakage of cytoplasm through photodamaged membranes, while longer incubation with low concentration of Photofrin leads to apoptotic response (Dellinger 1996). In our previous work we described distribution of Photofrin in several cell lines, including MCF-7 cells. We observed the most intensive signal around the nuclear envelope after $4 \mathrm{~h}$ of incubation. Photofrin-mediated PDT caused immediate cell death via apoptosis (Saczko et al. 2007, 2008).

Considering in vivo conditions, it was reported that both Photofrin-induced PDT alone and ECT alone were effective in breast cancer treatment. Photofrin-induced PDT, applied to breast cancer patients with chest wall progression, gave high response ratios allowing good long-term local tumor control (Cuenca et al. 2004). In other studies a high efficiency and a good safety profile of ECT with cisplatin or bleomycin, as an alternative approach for a treatment of chest wall breast cancer recurrence or cutaneous tumor lesions of breast cancer, were demonstrated (Rebersek et al. 2004; Sersa et al. 2012). Encouraged with these reports, we decided to investigate if a combination of Photofrin-induced PDT with EP may be an effective approach for breast cancer treatment. Additionally, for a comparison, we applied hamster ovarian cells lacking voltage-dependent channels, which are often used as reference cells in ECT. If electric pulses can enhance cellular uptake of Photofrin, combining PDT with EP would help to reduce effective dose of the photosensitizer and time of its accumulation, diminishing side effects of the therapy.

\section{Methods}

\section{Chemicals}

Photofrin was purchased from QLT PhotoTherapeutics, Inc., Vancouver, Canada. $10 \mathrm{mM}$ stock solution was prepared in MCF-7 culture medium. The final concentrations were obtained by direct dilution of the stock solution in the culture medium or EP buffer with low electrical conductivity (10 mM phosphate, $1 \mathrm{mM} \mathrm{MgCl}_{2}, 250 \mathrm{mM}$ sucrose, $\mathrm{pH}$ 7.4).

\section{Cell Culture}

The studies were performed on human breast adenocarcinoma cell line (MCF-7). Additionally, Chinese hamster ovary cells (CHO-WTT) were a model for transport studies on EP due to very low expression of endogenous ion channels (Gamper et al. 2005). MCF-7 cells were grown in RPMI 1640 (Eurobio, France) supplemented with $10 \%$ fetal bovine serum (Lonza, Switzerland), L-glutamine (Life Technologies, USA) and penicillin/streptomycin (Eurobio, France). MCF-7 cells were grown as a monolayer plated on a plastic flask $75 \mathrm{~cm}^{2}$ (Nunc, Denmark) and detached for the experiments by trypsinization (trypsin $0.025 \%$ EDTA $0.02 \%$ solution, Eurobio, France). CHO cells were grown in MEM (Eurobio, France) with appropriate supplementation, according to (Rols et al. 1995). CHO cells were grown in suspension in a spinner flask $(100 \mathrm{ml})$, placed on a stirring unit (IKA, Germany). Cells concentration was maintained in the range of $0.5-0.6 \times 10^{6}$ cells $/ \mathrm{ml}$. Cell culture was performed in a humidified atmosphere at $37{ }^{\circ} \mathrm{C}$ and $5 \% \mathrm{CO}_{2}$.

\section{Protocols}

\section{Spectra of Photofrin}

Solution of Photofrin in PBS with a concentration of $5 \mu \mathrm{M}$ (Eurobio) was prepared. Spectra of fluorescence excitation and emission were recorded with QM-4, Photon Technology International. Fluorescence excitation spectrum was recorded for the wavelength of emission of $615 \mathrm{~nm}$. Fluorescence emission spectrum was recorded for the wavelength of excitation of $500 \mathrm{~nm}$.

\section{Electroporation Procedure}

After trypsinization and centrifugation ( $5 \mathrm{~min}, 800 \mathrm{rpm}$, Centrifuge 5702R Eppendorf), cells were counted and for each sample of $0.5 \times 10^{6}$ cells they were resuspended in $100 \mu \mathrm{l}$ of EP buffer (10 mM phosphate (Sigma), $1 \mathrm{mM}$ $\mathrm{MgCl}_{2}$ (Sigma), $250 \mathrm{mM}$ sucrose (Sigma), $\mathrm{pH}$ 7.4). Cell suspension was pulsed in $35 \mathrm{~mm}$ Petri dishes (Nunc, Denmark), between two stainless-steel parallel plate electrodes, $4 \mathrm{~mm}$ distant. EP was performed using Betatech S20 (Betatech, L'union, France), which delivered five rectangular electrical pulses (different values of amplitude, pulse duration of $50 \mu \mathrm{s}$, frequency of $1 \mathrm{~Hz}$ ). The oscilloscope Enertec 5026 monitored the pulses. After pulsation, cells were left for $2 \mathrm{~min}$ at room temperature.

\section{Viability Assay}

Viability of electropermeabilized cells was assessed in the following way: $2 \mathrm{ml}$ of culture medium was added and cells were grown in Petri dishes for $24 \mathrm{~h}$ at $37{ }^{\circ} \mathrm{C}$ in $5 \% \mathrm{CO}_{2}$. Cell viability was determined by coloration, using crystal violet (Sigma) method. Cells were rinsed with PBS, incubated for 20 min with crystal violet solution, rinsed three times with PBS and incubated for 10 min with $10 \%$ acetic acid. After shaking, $50 \mu \mathrm{l}$ of cells were dissolved in acetic acid with $1 \mathrm{ml}$ of Milli-Q water. The absorbance of each sample was measured at $595 \mathrm{~nm}$ using Novaspec II, Pharmacia Biotech. The results were expressed as the percentage of viability, 
relative to untreated control cells (cells to which no dye was added and no pulses were applied). Three samples were prepared per each experiment. Mean values and standard deviations were calculated.

\section{Electropermeabilization Efficiency: Propidium Iodide Uptake}

Electropermeabilization efficiency was assessed by the penetration of impermeant dye-propidium iodide. Immediately before $\mathrm{EP}$, the cells were exposed to $100 \mu \mathrm{M}$ propidium iodide (PI, P4170, Sigma). Two minutes after pulsation cells were resuspended in $1 \mathrm{ml}$ of PBS. Samples were analyzed with a FACS Calibur flow cytometer (Becton-Dickinson) immediately after permeabilization.

\section{Electropermeabilization Efficiency: Photofrin Uptake}

Electropermeabilization of cells was quantified by the penetration of Photofrin. Immediately before EP, the cells were exposed to $25 \mu \mathrm{M}$ Photofrin. Two minutes after pulsation cells were resuspended in $1 \mathrm{ml}$ of PBS. Samples were analyzed immediately after permeabilization. Cellular uptake of Photofrin was examined under a fluorescent microscope and a flow cytometer.

Fluorescent Microscopy Studies Cells were observed under MacroFluo Leica Z16 APO with PLANAPO 5.0 $\times 1$ 0.50 LWD objective and 9.2 magnification (Leica, Germany). Exposure time was $10 \mathrm{~ms}$ (white light) and $1000 \mathrm{~ms}$ (fluorescent light). Cells were excited at $587 \mathrm{~nm}$, fluorescence emission was read at $610 \mathrm{~nm}$. Three images per condition were recorded. Images were analyzed with ImageJ software. The same brightness scale was set for all images in one experiment. Three-dimensional profiles of each single cell were obtained by the use of Interactive 3D Surface Plot Plugin to ImageJ software. Mean gray scale values were computed for each single cell in each fluorescent image separately and they were considered as equivalent of the fluorescent emission intensity of each single cell. Statistical analysis was performed with MATLAB 2011b (MathWorks). Statistical distribution of mean gray values was described with box plots. One box was created for each condition (each value of electric field intensity). In each box, the central mark is median, the edges of the box are the 25 and 75th percentiles, the whiskers extend to the most extreme data points not considered outliers, and outliers are plotted individually (marked with crosses).

Flow Cytometry Analysis Each sample was transferred to tube (Starlab, Switzerland) in ice and analyzed by flow cytometry (FACSCalibur, Becton-Dickinson) to determine the efficiency of electropermeabilization (the level of fluorescence associated with electropermeabilization). The samples were excited using the $488 \mathrm{~nm}$ line of an argon laser and detection of fluorescence was performed in FL-2 channel (for PI detection) or FL-3 channel (for Photofrin detection). Light-scatter and fluorescence measurements were used as an indication of an object size and shape, allowing for discrimination between cells, microspheres and debris. Data were analyzed using CellQuest software (Becton-Dickinson) and presented as the geometric mean of fluorescent emission intensities of the positive cells.

\section{Photodynamic Reaction Supported with Electroporation $(E P-P D R)$}

Before electric pulses delivery, proper volumes of Photofrin solution were added to the EP buffer. Then EP was performed. The whole experiment was conducted in dark conditions. One hour after EP cells were irradiated. Red (the whole spectrum from the range of $\sim 615-675 \mathrm{~nm}$ with the peak at $640 \mathrm{~nm}$ ), green (the whole spectrum from the range of $\sim 475-600 \mathrm{~nm}$ with the peak at $525 \mathrm{~nm}$ ) and blue (the whole spectrum from the range of $\sim 430-510 \mathrm{~nm}$ with the peak at $458 \mathrm{~nm}$ ) LED bulbs ( $2 \mathrm{~W}$ of power) were used as a light source. When cells were irradiated with mixed light, three lamps simultaneously delivered red, green and blue light, so the power of light was three fold greater. Samples were irradiated for $10 \mathrm{~min}$ in sterile conditions. Petri dish without a cover was placed on a mirror to double the light. Viability of cells was measured $24 \mathrm{~h}$ after the end of experiment. Dark EP-PDR experiment was a non-irradiated control for EP-PDR.

\section{Statistical Analysis}

The results of the crystal violet assay and FACS analysis were reported as mean \pm standard deviation. The significance of the difference between mean values of different groups of cells was assessed by Student's $t$ test with $p$ value of $p \leq 0.05$ or $p \leq 0.005$, to show the statistical significance.

\section{Results}

\section{Spectra of Photofrin}

Fluorescence spectra of Photofrin are presented in Fig. 1. The maximum of excitation occurred at approximately $500 \mathrm{~nm}$, two other peaks were measured at 540 and $560 \mathrm{~nm}$. The maximum of emission occurred at $615 \mathrm{~nm}$, the second peak was measured at $\sim 680 \mathrm{~nm}$. Recorded spectra were used to select a proper wavelength range for Photofrin excitation. 


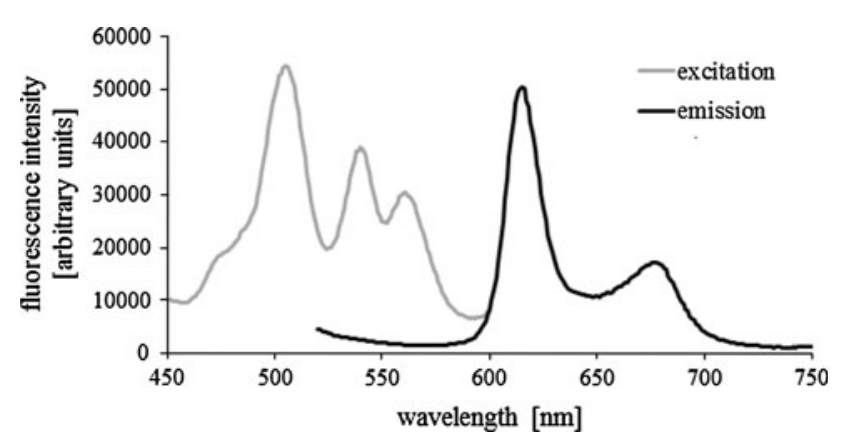

Fig. 1 Fluorescence excitation and emission spectra of Photofrin ( $5 \mu \mathrm{M}$ in PBS)

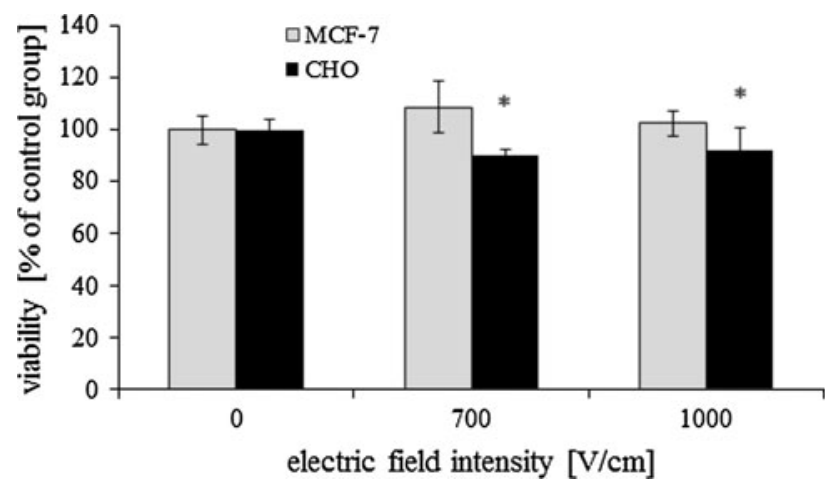

Fig. 2 Viability of $\mathrm{CHO}$ and MCF-7 cells after electroporation (5 pulses with a duration of $50 \mu$ s were delivered at the frequency of $1 \mathrm{~Hz}$; crystal violet method was performed $24 \mathrm{~h}$ after electroporation); $* p<0.05$

Sensitivity to Electropermeabilization

Sensitivity to electropermeabilization was evaluated for both cell lines and presented in Fig. 2. The electric field in the studied range of intensities was not toxic for MCF-7 cells. The viability even after EP at $1000 \mathrm{~V} / \mathrm{cm}$ was unaffected. CHO cells viability slightly decreased with electric field intensity. When cells were electroporated at $1000 \mathrm{~V} / \mathrm{cm}$, their viability was still high-ca. $90 \%$.

\section{Electropermeabilization Efficiency: Propidium Iodide Uptake}

Efficiency of MCF-7 and CHO cells electropermeabilization was assessed by propidium iodide uptake. Figure 3 presents flow cytometry results. Both cell lines revealed enhanced PI accumulation after electric pulses delivery. Geometric mean of fluorescence intensity increased with electric field intensity. Particularly high fluorescence was measured in cells electroporated at $1000 \mathrm{~V} / \mathrm{cm}$. The whole population was shifted towards higher fluorescence values.

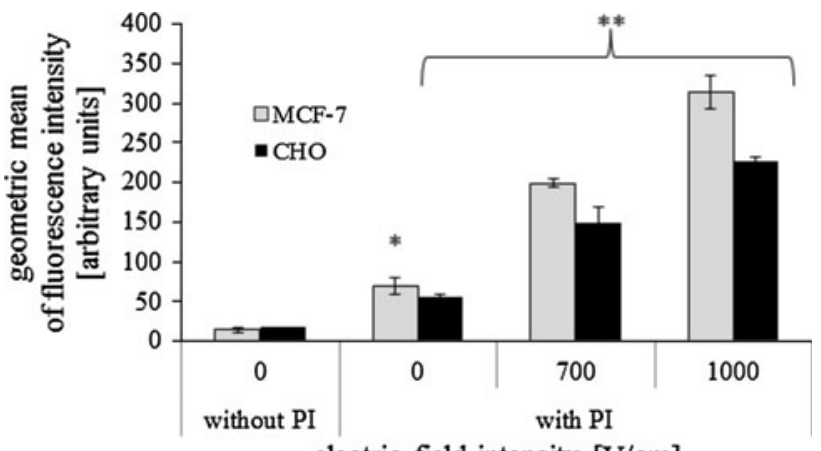

electric field intensity $[\mathrm{V} / \mathrm{cm}]$

Fig. 3 Geometric mean of fluorescence intensity measured in cells electropermeabilized with $100 \mu \mathrm{M}$ propidium iodide (flow cytometry results; 5 pulses with a duration of $50 \mu$ s were delivered at a frequency of $1 \mathrm{~Hz}$ ); $* p<0.05, * * p<0.005$

\section{Electropermeabilization Efficiency: Photofrin Uptake}

Images of $\mathrm{CHO}$ cells with Photofrin are presented in Fig. 4. These results show enhanced Photofrin uptake after electric pulses application. For cells electroporated with Photofrin at $1000 \mathrm{~V} / \mathrm{cm}$, strong fluorescence intensity was observed, in contrast to non-electroporated cells.

For MCF-7 cells, the fluorescence intensity of electroporated cells was also higher than the intensity of nonelectroporated cells (Fig. 5). More molecules of Photofrin entered the cell after the cell membrane permeabilization.

In Figs. 6 and 7, three-dimensional profiles of single cells are presented. For non-electroporated $\mathrm{CHO}$ cell very low fluorescence intensity was measured (Fig. 6). When cells were electroporated, fluorescence increased with the electric field intensity. For the electric field intensity of $700 \mathrm{~V} / \mathrm{cm}$, the results were not clear. One group of cells showed enhanced Photofrin accumulation (Fig. 6c), while the second one did not exhibit any significant differences in comparison with nonelectropermeabilized cells (Fig. 6b). The value of $1000 \mathrm{~V} / \mathrm{cm}$ was the most effective and enabled Photofrin molecules enter the cell.

Figure 7 presents profiles of MCF-7 cells. Non-electroporated cell also did not exhibit a significant fluorescence. The fluorescence intensity detected in MCF-7 cells electroporated with Photofrin was not as high as in $\mathrm{CHO}$ cells; however, intensive fluorescence was observed in nuclear area of the cell.

Figures 8 and 9 present statistical analysis based on the fluorescent microscopic images of cells exposed to Photofrin. For CHO cells (Fig. 8) the box plot shows an increase of median of fluorescence intensity with increasing electric field intensity. Particularly high fluorescence intensity was measured for cells electroporated at $1000 \mathrm{~V} / \mathrm{cm}$ (median at the level of approximately 660 units). For non-electroporated $\mathrm{CHO}$ cells fluorescence intensity reached the level of approximately 380 units. For 
Fig. $4 \mathrm{CHO}$ cells

electropermeabilized with $25 \mu \mathrm{M}$ Photofrin (fluorescent microscopy results; 5 pulses with a duration of $50 \mu$ s were delivered at a frequency of $1 \mathrm{~Hz}$ )

Fig. 5 MCF-7 cells electropermeabilized with $25 \mu \mathrm{M}$ Photofrin (fluorescent microscopy results; 5 pulses with a duration of $50 \mu$ s were delivered at a frequency of $1 \mathrm{~Hz}$ )
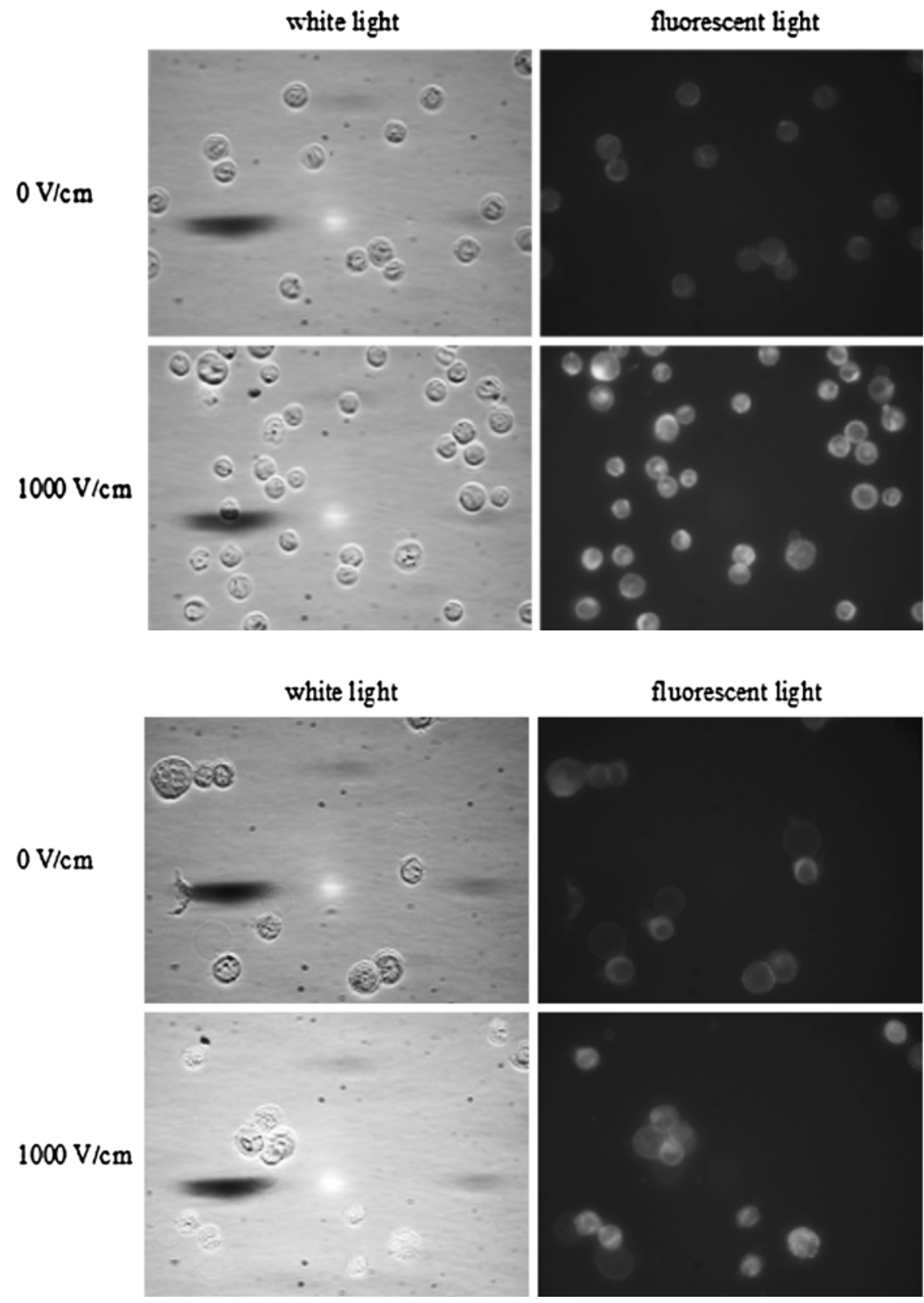

MCF-7 cells median of fluorescence intensity increased with electric field intensity (Fig. 9). The fluorescence intensity of non-electroporated MCF-7 cells was $\sim 390$ units, after EP at $1000 \mathrm{~V} / \mathrm{cm}$ it increased to $\sim 500$ units. The results of flow cytometry are consistent with the previously presented microscopy images analysis (Fig. 10). Fluorescence intensity of MCF-7 cells, electroporated with Photofrin, is higher than that of non-electroporated cells exposed to the photosensitizer. However, it did not increase as significantly with electric field as it could be expected (fluorescence intensity of non-electroporated cells treated with Photofrin was at the level of 90 units, after EP at $700 \mathrm{~V} / \mathrm{cm}$ it reached the level of 140 units).
Photodynamic Reaction Supported with Electroporation (EP-PDR)

The influence of EP with Photofrin on cells viability was evaluated. Figure 11 presents results of "dark EP-PDR" on $\mathrm{CHO}$ cells. The concentration of Photofrin and the time of incubation before irradiation used in our study (5 and $25 \mu \mathrm{M}, 1 \mathrm{~h}$ ) were lower than in standard PDT in vitro without EP. Without irradiation both studied concentrations of Photofrin were non-toxic for $\mathrm{CHO}$ cells. Even when pulses at electric field intensity of $1000 \mathrm{~V} / \mathrm{cm}$ were applied, cells viability remained above $90 \%$. 

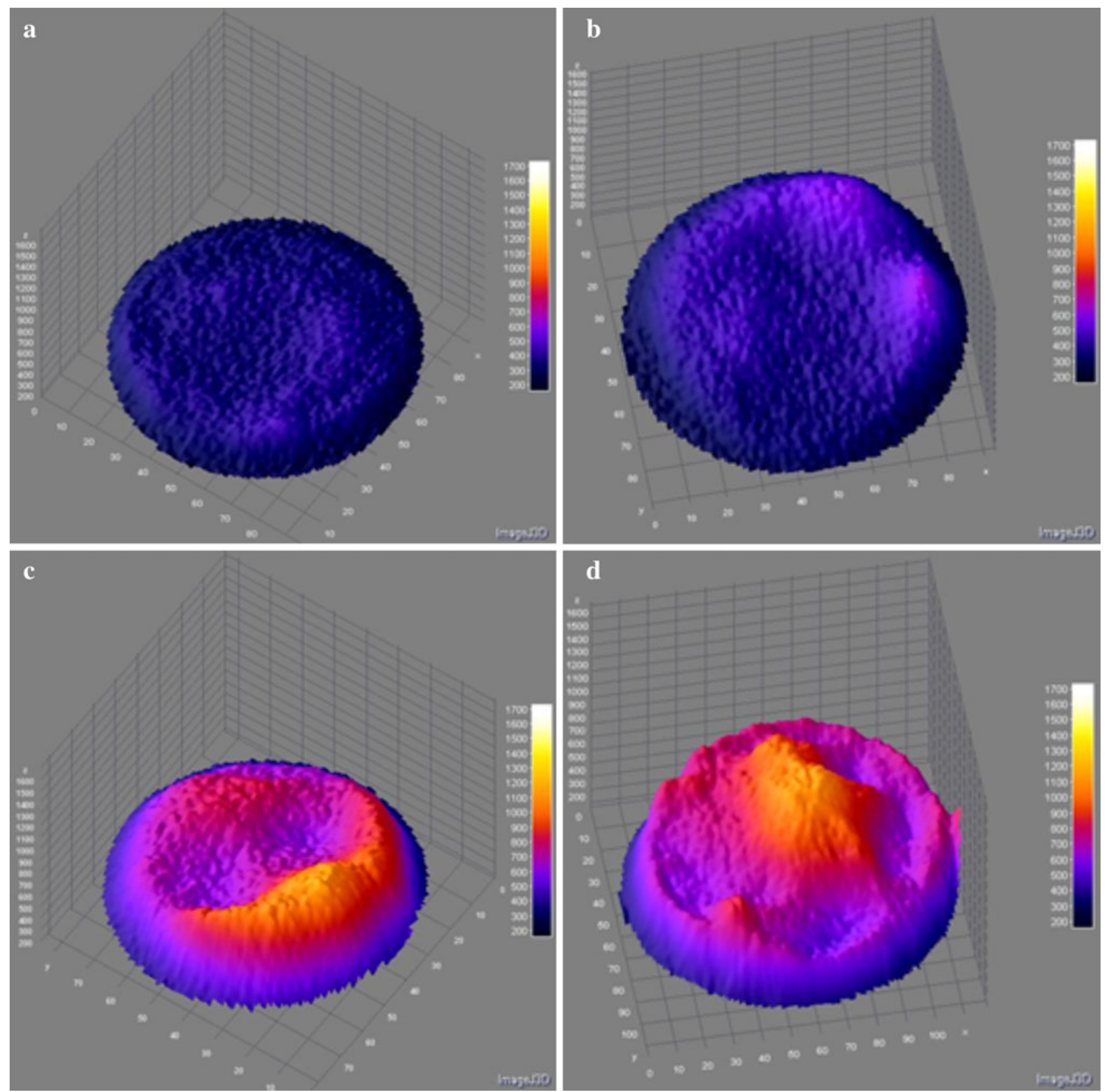

Fig. 6 3D profiles of $\mathrm{CHO}$ cells electropermeabilized with $25 \mu \mathrm{M}$ Photofrin: a $0 \mathrm{~V} / \mathrm{cm}, \mathbf{b}, \mathbf{c} 700 \mathrm{~V} / \mathrm{cm}$, d $1000 \mathrm{~V} / \mathrm{cm}$ (fluorescent microscopy results; 5 pulses with a duration of $50 \mu$ s were delivered at a frequency of $1 \mathrm{~Hz}$ )

Viability of MCF-7 cells electroporated with Photofrin $(25 \mu \mathrm{M})$, both without and with irradiation, was determined. Electric field intensities of 700, 1000 and $1200 \mathrm{~V} / \mathrm{cm}$ were selected. The results are presented in Fig. 12. Viability of non-electroporated cells incubated with Photofrin without irradiation and irradiated with mixed, red and green light was even higher than viability of untreated control cells. Only when cells were irradiated with blue light, their viability decreased, although it remained above $80 \%$. When electric pulses were additionally applied, cells viability decreased for both dark and irradiated conditions. Toxic influence of the combination of EP with Photofrin and blue light irradiation was particularly significant. Even at the lowest electric field intensity $(700 \mathrm{~V} / \mathrm{cm})$ effectiveness of EP-PDR was very high — cells viability decreased below $20 \%$. It should be noted that Photofrin-mediated PDT of cancer cells is effective even without EP; however, in our experiment the incubation time was much shorter than what is usually applied. 

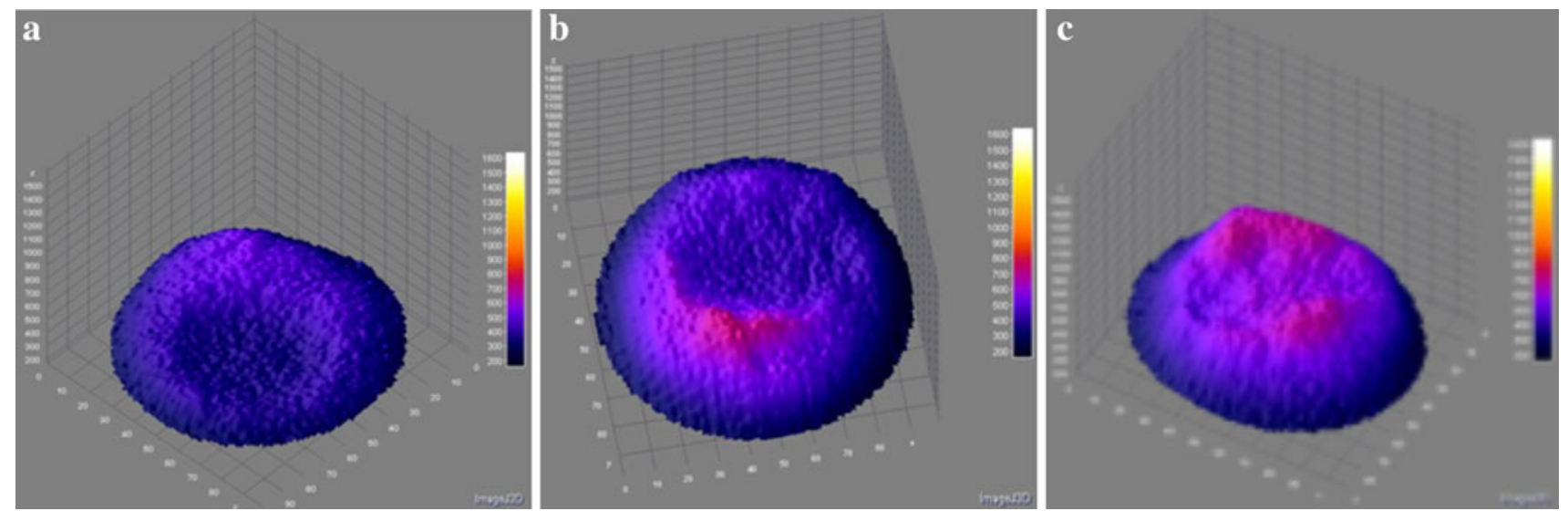

Fig. 7 3D profiles of electropermeabilized MCF-7 cells with $25 \mu \mathrm{M}$ Photofrin: a $0 \mathrm{~V} / \mathrm{cm}, \mathbf{b} 700 \mathrm{~V} / \mathrm{cm}$, c $1000 \mathrm{~V} / \mathrm{cm}$ (fluorescent microscopy results; 5 pulses with a duration of $50 \mu$ s were delivered at a frequency of $1 \mathrm{~Hz}$ )

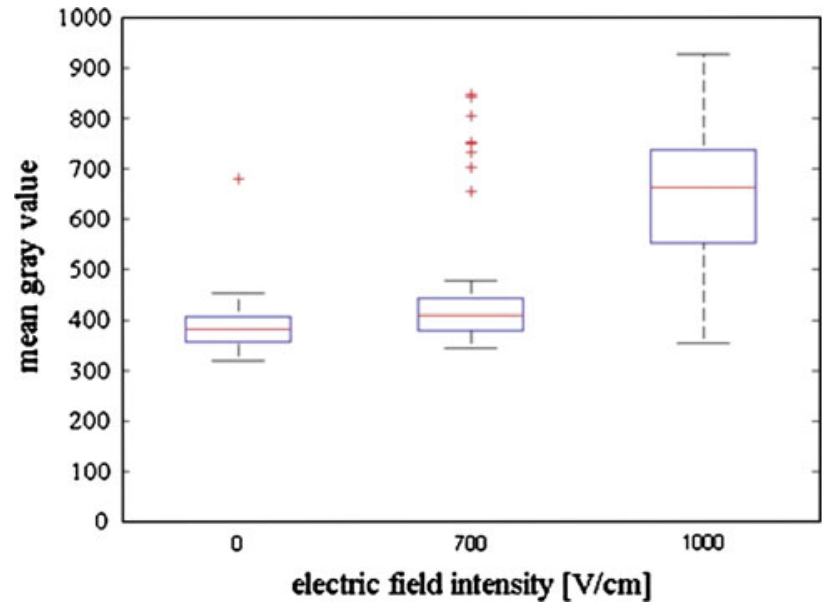

Fig. 8 Box plot of mean grey value calculated for $\mathrm{CHO}$ cells electropermeabilized with $25 \mu \mathrm{M}$ Photofrin (statistical parameters calculated on the basis of fluorescent microscopy results; 5 pulses with a duration of $50 \mu$ s were delivered at a frequency of $1 \mathrm{~Hz}$ ); in each box, the central mark is median, the edges of the box are the 25 and 75th percentiles, the whiskers extend to the most extreme data points not considered outliers, and outliers are plotted individually (crosses)

\section{Discussion}

In this work we presented an innovative approach to Photofrin-mediated PDT assisted by electric field. The results show that cells viability did not decrease after electric pulses delivery (Fig. 2), which demonstrates that EP is not toxic if appropriate parameters are used. The uptake of propidium iodide (impermeant dye) increased with electric field intensity (Fig. 3), demonstrating enhanced cell membrane permeabilization.

The main objective of this study was to observe the influence of electric pulses delivery on the Photofrin uptake and its localization in MCF-7 and CHO cells. On the basis

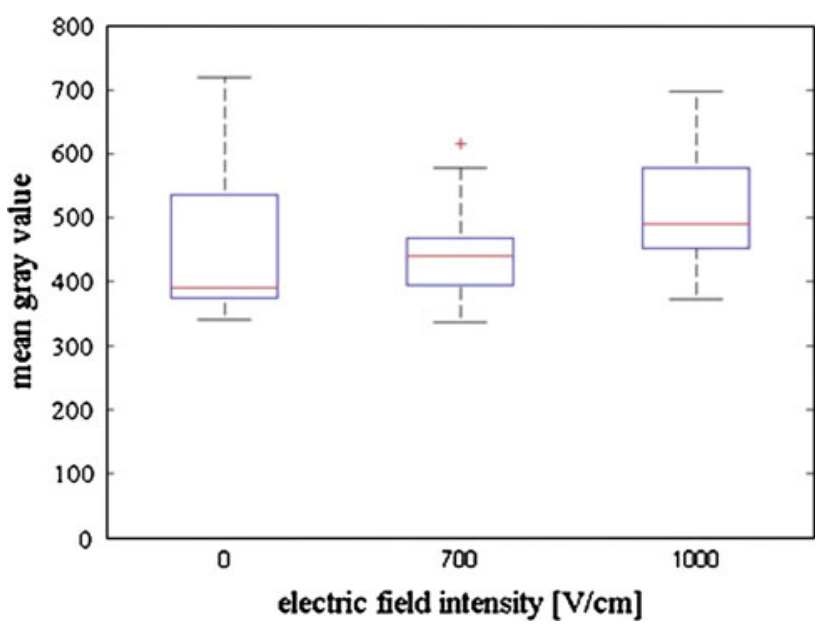

Fig. 9 Box plot of mean grey value calculated for MCF-7 cells electropermeabilized with $25 \mu \mathrm{M}$ Photofrin (statistical parameters calculated on the basis of fluorescent microscopy results; 5 pulses with a duration of $50 \mu$ s were delivered at a frequency of $1 \mathrm{~Hz}$ ); in each box, the central mark is median, the edges of the box are the 25 and 75th percentiles, the whiskers extend to the most extreme data points not considered outliers, and outliers are plotted individually (crosses)

of the fluorescence images analysis, we observed that EP of CHO cells significantly improved Photofrin uptake (Figs. 4, $6,8)$. Due to electropermeabilization, Photofrin entered the cell and accumulated in the whole cell. For MCF-7 cells an increased accumulation was also observed, but not as effective as for CHO cells (Figs. 5, 7, 9, 10). It may have resulted from different properties of these cell lines. Chinese hamster ovary cells are a common model for transport studies on EP due to very low expression of endogenous ion channels (Gamper et al. 2005). In contrast, the expression of a number of voltage-gated potassium channels in MCF-7 cells has been demonstrated (Minghua and Zhi-Gang 2011; Van Tol et al. 2007; Wonderlin et al. 1995). Voltage-gated 


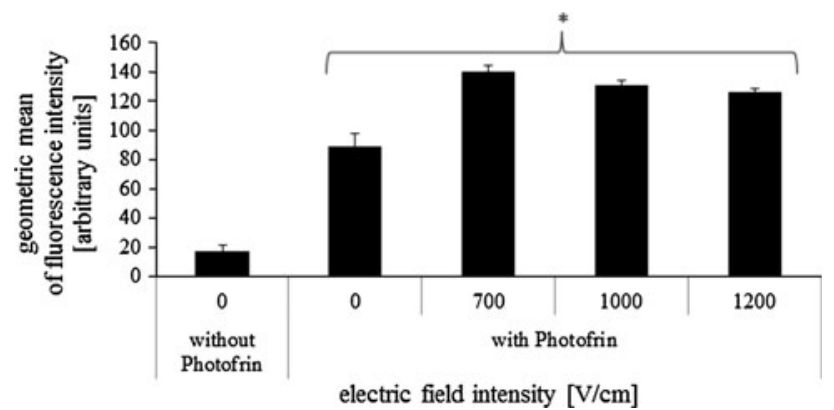

Fig. 10 Geometric mean of fluorescence intensity of MCF-7 cells electropermeabilized with $25 \mu \mathrm{M}$ Photofrin (flow cytometry results; 5 pulses with a duration of $50 \mu$ s were delivered at a frequency of $1 \mathrm{~Hz}) ; * p<0.005$

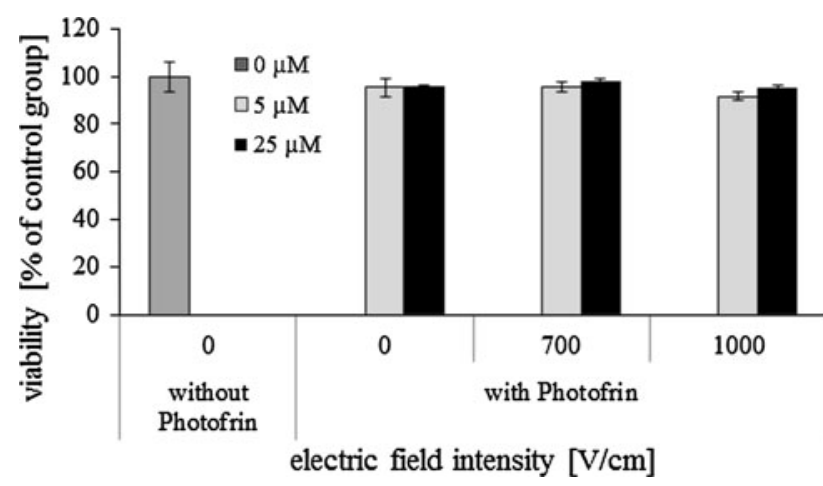

Fig. 11 Viability of $\mathrm{CHO}$ cells after dark EP-PDR with Photofrin $(5$ and $25 \mu \mathrm{M})(5$ pulses with a duration of $50 \mu$ s were delivered at a frequency of $1 \mathrm{~Hz}$; crystal violet method was performed $24 \mathrm{~h}$ after electroporation)

sodium channels were also identified in MCF-7 cells. Interestingly, the overall level of its expression was $>100$ fold higher in strongly metastatic MDA-MB-231 human breast cancer cells compared with weakly metastatic MCF7 cells (Fraser et al. 2005). In general, ion channels attract attention of researchers as potential markers of oncogenic events and new targets of anticancer therapy (Le Guennec et al. 2007). It would be valuable to explore in detail the possible implications of expression of voltage-dependent ion channels on the uptake of drugs in MCF-7 cells.

In addition to the assessment of Photofrin transport enhancement, we also evaluated the influence of Photofrin mediated PDT, assisted by EP, on MCF-7 cells viability (Fig. 12).

Viability of non-electroporated cells incubated with Photofrin without irradiation and irradiated with mixed, red and green light was even higher than viability of untreated control cells. We assume that without EP Photofrin molecules did not manage to enter the cells due to very short time of incubation $(1 \mathrm{~h})$. Moreover, without irradiation (or upon irradiation with a light of improper wavelength)

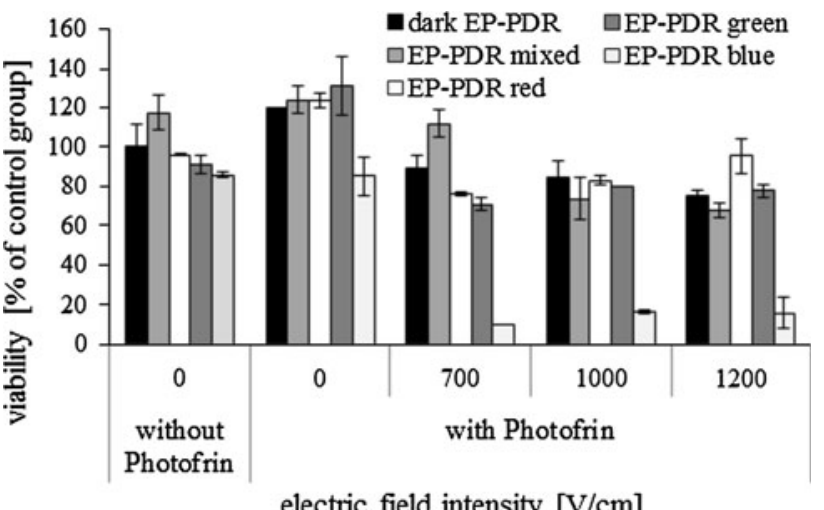

electric field intensity $[\mathrm{V} / \mathrm{cm}]$

Fig. 12 Viability of MCF-7 cells after EP-PDR with $25 \mu \mathrm{M}$ Photofrin ( 5 pulses with a duration of $50 \mu$ s were delivered at a frequency of $1 \mathrm{~Hz}$; cells were irradiated with red, green, blue and mixed light or nonirradiated; crystal violet method was performed $24 \mathrm{~h}$ after electroporation) (Color figure online)

Photofrin was not activated and the process of cell destruction could not begin. Cell proliferation was not hampered. Maybe in the presence of drug some kind of self-defense mechanisms of cells were activated, resulting in even slightly higher viability than in the control group. Only upon irradiation with blue light did MCF-7 cell viability decrease, although it remained above $80 \%$. Cells viability decreased for both dark and irradiated conditions when electric pulses were additionally applied. The most efficient cell viability decrease was achieved when cells electroporated with Photofrin were irradiated with the blue light. The viability of cells electroporated with Photofrin at the lowest electric field intensity $(700 \mathrm{~V} / \mathrm{cm})$ decreased below $20 \%$ after irradiation with the blue light. Irradiation with mixed, green or red light was not effective, the same results were obtained for "dark EP-PDR" experiment. The viability of nonirradiated (or irradiated with mixed, green or red light) cells decreased when electric pulses were delivered, but it was still at the level $\sim 70 \%$.

Many authors showed that Photofrin mediated PDT is effective even without EP but much longer times of incubation or higher concentrations of Photofrin should be applied: 4 h, $40 \mu \mathrm{M}$ (Hajri et al. 2002); 16 h, $4 \mu \mathrm{M}$ (Luo et al. 2010); $18 \mathrm{~h}, 2.5-13 \mu \mathrm{M}$ (Tong et al. 2000); $18 \mathrm{~h}$, 2-15 $\mu \mathrm{M}$ (Wilson et al. 1997); $24 \mathrm{~h}, 34 \mu \mathrm{M}$ (Korbelik et al. 1991). In our studies cell were exposed to Photofrin only for $1 \mathrm{~h}$ before irradiation. EP facilitated transport of Photofrin and allowed to reduce the time required for intracellular accumulation. This reduction is of huge importance for potential clinical application since reduced time interval between drug delivery and tumor irradiation may limit skin sensitivity to sunlight, which normally occurs after Photofrin-mediated PDT. 


\section{Conclusions}

The efficiency of PDT depends on efficient uptake of the photosensitizer by cells. EP of cells enables creation of new ways of molecular transport. Using this phenomenon to photosensitizers delivery can improve PDT effectiveness and reduce drug dose. Moreover, selectivity of PDT can also be improved, as permeabilization occurs only near the area of pulses delivery. All these factors help to diminish side effects of chemotherapy.

Our study showed that the delivery assisted with electric pulses enhances Photofrin uptake by cells in vitro. A combination of photodynamic reaction with EP improved the PDR effectiveness by decrease of cell proliferation and increased nuclear accumulation of photosensitizer after EP. It is interesting that even at the low electric field intensity $(700 \mathrm{~V} / \mathrm{cm})$ Photofrin transport was enhanced. Due to Photofrin anionic character, transport through ion channels or by electrophoresis may also be considered. Undoubtedly, PDT assisted by electric field is an attractive, innovative approach for cancer treatment. However, detailed studies on the mechanism of Photofrin uptake are necessary.

Acknowledgments JW and MBD would like to thank SocratesErasmus Programme. This research was partially conducted in the framework of COST Action TD1104, National Science Centre, Grant 2011/01/D/NZ4/01255, and grant 219/2012 for BioNanopore Students Association from Wroclaw University of Technology. The fluorescence measurements in Toulouse were done with the TRI core facility at the IPBS (Genotoul, Toulouse, France), which is supported by the Association Recherche Cancer, Region Midi Pyrenees and Grand Toulouse cluster.

Open Access This article is distributed under the terms of the Creative Commons Attribution License which permits any use, distribution, and reproduction in any medium, provided the original author(s) and the source are credited.

\section{References}

Agostinis P, Berg K, Cengel KA, Foster TH, Girotti AW, Gollnick SO, Hahn SM, Hamblin MR, Juzeniene A, Kessel D, Korbelik M, Moan J, Mroz P, Nowis D, Piette J, Wilson BC, Golab J (2011) Photodynamic therapy of cancer: an update. CA Cancer J Clin 61:250-281

Berg K, Golab J, Korbelik M, Russell D (2011) Drug delivery technologies and immunological aspects of photodynamic therapy. Photochem Photobiol Sci 10:647-648

Chabot S, Orio J, Schmeer M, Schleef M, Golzio M, Teissie J (2013) Minicircle DNA electrotransfer for efficient tissue-targeted gene delivery. Gene Ther 20:62-66

Chang CJ, Yu JS, Wei FC (2008) In vitro and in vivo photosensitizing applications of Photofrin in malignant melanoma cells. Chang Gung Med J 31:260-266

Choudhary S, Nouri K, Elsaie ML (2009) Photodynamic therapy in dermatology: a review. Lasers Med Sci 24:971-980
Chwiłkowska A, Saczko J, Modrzycka T, Marcinkowska A, Malarska A, Bielewicz J, Patalas D, Banaś T (2003) Uptake of Photofrin II, a photosensitizer used in photodynamic therapy, by tumour cells in vitro. Acta Biochim Pol 50:509-513

Cuenca RE, Allison RR, Sibata C, Downie GH (2004) Breast cancer with chest wall progression: treatment with photodynamic therapy. Ann Surg Oncol 11:322-327

Davalos R, Mir L, Rubinsky B (2005) Tissue ablation with irreversible electroporation. Ann Biomed Eng 33:223-231

Dellinger M (1996) Apoptosis or necrosis following Photofrin photosensitization: influence of the incubation protocol. Photochem Photobiol 64:182-187

Donnelly RF, McCarron PA, Woolfson D (2009) Drug delivery systems for photodynamic therapy. Recent Pat Drug Deliv Formul 3:1-7

Ferreira J, Menezes PFC, Sibata CH, Allison RR, Zucoloto S, Castro e Silva O, Bagnato VS (2009) Can efficiency of the photosensitizer be predicted by its photostability in solution? Laser Phys 19:1932-1938

Fraser SP, Diss JKJ, Chioni AM, Mycielska ME, Pan H, Yamaci RF, Pani F, Siwy Z, Krasowska M, Grzywna Z, Brackenbury WJ, Theodorou D, Koyuturk M, Kaya H, Battaloglu E, Tamburo De Bella M, Slade MJ, Tolhurst R, Palmieri C, Jiang J, Latchman DS, Coombes RC, Djamgoz MBA (2005) Voltage-gated sodium channel expression and potentiation of human breast cancer metastasis. Clin Cancer Res 11:5381-5389

Gamper N, Stockand JD, Shapiro MS (2005) The use of Chinese hamster ovary $(\mathrm{CHO})$ cells in the study of ion channels. J Pharmacol Toxicol Methods 51:177-185

Gehl J (2003) Electroporation: theory and methods, perspectives for drug delivery, gene therapy and research. Acta Physiol Scand 177:437-447

Hajri A, Wack S, Meyer C, Smith MK, Leberquier C, Kedinger M, Aprahamian M (2002) In vitro and in vivo efficacy of Photofrin and pheophorbide a, a bacteriochlorin, in photodynamic therapy of colonic cancer cells. Photochem Photobiol 75:140-148

Henderson BW, Busch TM, Vaughan LA, Frawley NP, Babich D, Sosa TA, Zollo JD, Dee AS, Cooper MT, Bellnier DA, Greco WR, Oseroff AR (2000) Photofrin photodynamic therapy can significantly deplete or preserve oxygenation in human basal cell carcinomas during treatment, depending on fluence rate. Cancer Res 60:525-529

Hsieh YJ, Wu CC, Chang CJ, Yu JS (2003) Subcellular localization of Photofrin determines the death phenotype of human epidermoid carcinoma A431 cells triggered by photodynamic therapy: when plasma membranes are the main targets. J Cell Physiol 194:363-375

Jiang F, Lilge L, Grenier J, Li Y, Wilson MD, Chopp M (1998) Photodynamic therapy of U87 human glioma in nude rat using liposome-delivered Photofrin. Lasers Surg Med 22:74-80

Johnson PG, Gallo SA, Hui SW, Oseroff AR (1998) A pulsed electric field enhances cutaneous delivery of methylene blue in excised full-thickness porcine skin. J Investig Dermatol 11:457-463

Johnson PG, Hui SW, Oseroff AR (2002) Electrically enhanced percutaneous delivery of $\delta$-aminolevulinic acid using electric pulses and a DC potential. Photochem Photobiol 75:534-540

Josefsen LB, Boyle RW (2008) Photodynamic therapy and the development of metal-based photosensitisers. In: Swarts JC, Cook MJ, Baker EN (eds) Metal-containing Proteins, Macrocycles, and Coordination Complexes in Therapeutic Applications and Disease. Hindawi Publishing, Cairo, pp 10-33

Juzeniene A, Peng Q, Moan J (2007) Milestones in the development of photodynamic therapy and fluorescence diagnosis. Photochem Photobiol Sci 6:1234-1245

Kanduser M, Miklavcic D (2008) Electroporation in biological cell and tissue: an overview. In: Vorobiev E, Lebovka $\mathrm{N}$ (eds) 
Electrotechnologies for extraction from food plants and biomaterials. Springer, New York, pp 237-269

Korbelik M, Krosl G (1996) Photofrin accumulation in malignant and host cell populations of various tumours. Br J Cancer 73: 506-513

Korbelik M, Krosl G, Chaplin DJ (1991) Photofrin uptake by murine macrophages. Cancer Res 51:2251-2255

Kotulska M (2007) Electrochemotherapy in cancer treatment. Adv Clin Exp Med 16:601-607

Kotulska M, Kulbacka J, Saczko J (2013) Advances in photodynamic therapy assisted by electroporation. Curr Drug Metab 14: 309-318

Kulbacka J, Chwilkowska A, Bar J, Pola A, Banas T, Gamian A, Saczko J (2010) Oxidative alterations induced in vitro by the photodynamic reaction in doxorubicin-sensitive (LoVo) and -resistant (LoVoDX) colon adenocarcinoma cells. Exp Biol Med 235:98-110

Kulbacka J, Nowak M, Skołucka N, Saczko J, Kotulska M (2011) The influence of electroporation on in vitro photodynamic therapy of human breast carcinoma cells. Folia Biol (Praha) 57:112-118

Labanauskiene J, Satkauskas S, Kirveliene V, Venslauskas M, Atkocius V, Didziapetriene J (2009) Enhancement of photodynamic tumor therapy effectiveness by electroporation in vitro. Medicina (Kaunas) 45:372-377

Lambreva M, Gluck B, Radeva M, Berg H (2004) Electroporation of cell membranes supporting penetration of photodynamic active macromolecular chromophore dextrans. Bioelectrochemistry 62:95-98

Le Guennec JY, Ouadid-Ahidouch H, Soriani O, Besson P, Ahidouch A, Vandier C (2007) Voltage-gated ion channels: new targets in anti-cancer research. Recent Pat Anticancer Drug Discov 2: 189-202

Luo S, Xing D, Wei Y, Chen Q (2010) Inhibitive effects of Photofrin on cellular autophagy. J Cell Physiol 224:414-422

Marchal S, Francois A, Dumas D, Guillemin F, Bezdetnaya F (2007) Relationship between subcellular localization of Foscan and caspase activation in photosensitized MCF-7 cells. Br J Cancer 96:944-951

Miklavcic D, Sersa G, Brecelj E, Gehl J, Soden D, Bianchi G, Ruggieri P, Rossi CR, Campana LG, Jarm T (2012) Electrochemotherapy: technological advancements for efficient electroporation-based treatment of internal tumors. Med Biol Eng Comput 50:1213-1225

Minghua L, Zhi-Gang X (2011) Ion channels as targets for cancer therapy. Int J Physiol Pathophysiol Pharmacol 3:156-166

Mir LM (2006) Bases and rationale of the electrochemotherapy. Eur J Cancer 4:38-44

Morgan J, Oseroff AR (2001) Mitochondria-based photodynamic anti-cancer therapy. Adv Drug Deliv Rev 49:71-86

Peng Q, Moan J, Nesland JM (1996) Correlation of subcellular and intratumoral photosensitizer localization with ultrastructural features after photodynamic therapy. Ultrastruct Pathol 20: 109-129

Rebersek M, Cufer T, Cemazar M, Kranjc S, Sersa G (2004) Electrochemotherapy with cisplatin of cutaneous tumor lesions in breast cancer. Anticancer Drugs 15:593-597

Robertson CA, Evans DH, Abrahamse H (2009) Photodynamic therapy (PDT): a short review on cellular mechanisms and cancer research applications for PDT. J Photochem Photobiol B 96:1-8

Rodriguez ME, Azizuddin K, Zhang P, Chiu S, Lam M, Kenney ME, Burda C, Oleinick NL (2008) Targeting of mitochondria by $10-\mathrm{N}$-alkyl acridine orange analogues: role of alkyl chain length in determining cellular uptake and localization. Mitochondrion $8: 237-246$

Rols MP (2006) Electropermeabilization, a physical method for the delivery of therapeutic molecules into cells. Biochim Biophys Acta 1758:423-428

Rols MP (2010) Gene transfer by electrical fields. Curr Gene Ther 10:255

Rols MP, Femenia P, Teissie J (1995) Long-lived macropinocytosis takes place in electropermeabilized mammalian cells. Biochem Biophys Res Commun 208:26-35

Saczko J, Mazurkiewicz M, Chwiłkowska A, Kulbacka J, Kramer G, Ługowski M, Snietura M, Banaś T (2007) Intracellular distribution of Photofrin in malignant and normal endothelial cell lines. Folia Biol (Praha) 53:7-12

Saczko J, Chwiłkowska A, Kulbacka J, Berdowska I, Zieliński B, Drąg-Zalesińska M, Wysocka T, Ługowski M, Banaś T (2008) Photooxidative action in cancer and normal cells induced by the use of Photofrin in photodynamic therapy. Folia Biol (Praha) 54:24-29

Samia ACS, Dayal S, Burda C (2006) Quantum dot-based energy transfer: perspectives and potential for applications in photodynamic therapy. Photochem Photobiol 82:617-625

Schweitzer VG (2001) Photofrin-mediated photodynamic therapy for treatment of early stage oral cavity and laryngeal malignancies. Lasers Surg Med 29:305-313

Sersa G, Cufer T, Paulin SM, Cemazar M, Snoj M (2012) Electrochemotherapy of chestwall breast cancer recurrence. Cancer Treat Rev 38:379-386

Serša G, Miklavčič D, Cemazar M, Rudolf Z, Pucihar G, Snoj M (2008) Electrochemotherapy in treatment of tumours. Eur J Surg Oncol 34:232-240

Stamati I, Kuimova MK, Lion M, Yahioglu G, Phillips D, Deonarain MP (2010) Novel photosensitisers derived from pyropheophorbide a: uptake by cells and photodynamic efficiency in vitro. Photochem Photobiol Sci 9:1033-1041

Sukharev SI, Klenchin VA, Serov SM, Chernomordik LV, Chizmadzhev YA (1992) Electroporation and electrophoretic DNA transfer into cells. The effect of DNA interaction with electropores. Biophys J 63:1320-1327

Teiten MH, Bezdetnaya L, Merlin JL, Bour-Dill C, Pauly ME, Dicato M, Guillemin F (2001) Effect of meta-tetra(hydroxyphenyl)chlorine (mTHPC)-mediated photodynamic therapy on sensitive and multidrug-resistant human breast cancer cells. J Photochem Photobiol B 62:146-152

Tong Z, Singh G, Rainbow AJ (2000) The role of the p53 tumor suppressor in the response of human cells to Photofrin-mediated photodynamic therapy. Photochem Photobiol 71:201-210

Van Tol BL, Missan S, Crack J, Moser S, Baldridge WH, Linsdell P, Cowley EA (2007) Contribution of KCNQ1 to the regulatory volume decrease in the human mammary epithelial cell line MCF-7. Am J Physiol Cell Physiol 293:1010-1019

Ward T, Mooney D, Flynn G, McHale AP (1997) Electric fieldenhanced activation of hematoporphyrin derivative: effects on a human tumour cell line. Cancer Lett 113:145-151

Wilson BC, Olivo M, Singh G (1997) Subcellular localization of Photofrin and aminolevulinic acid and photodynamic crossresistance in vitro in radiation-induced fibrosarcoma cells sensitive or resistant to Photofrin-mediated photodynamic therapy. Photochem Photobiol 65:166-176

Wonderlin WF, Woodfork KA, Strobl JS (1995) Changes in membrane potential during the progression of MCF-7 human mammary tumor cells through the cell cycle. J Cell Physiol 165:177-185 